\title{
Atopobium vaginae: a literature review on findings and potential clinical implications
}

\author{
Andrea Mariano ${ }^{1}$, Angelo Salzo', Valentina Felice ${ }^{2}$, Massimiliano Scutellà ${ }^{2}$ \\ ${ }^{1}$ Department of Medicine and Health Sciences "V. Tiberio", University of Molise, Campobasso; ${ }^{2}$ Complex Operating \\ Unit of Laboratory Medicine, Civil Hospital "A. Cardarelli”, Campobasso, Italy
}

\section{Summary}

Atopobium vaginae is an anaerobic Gram-positive bacterium. It is recognized as a causal agent of bacterial vaginosis onset and occasionally associated to gynaecologic-obstetric complications (including pelvic inflammatory disease, endometritis, tubo-ovarian abscesses and preterm delivery with neonatal consequences). Additionally, bacteraemia and invasive infections have rarely been reported. The scientific and technological progress allowed an accurate and rapid identification of Atopobium vaginae supporting diagnosis and clinic interventions. In this article, literature has been deeply examined to report the state-of-the-art on Atopobium vaginae, which might be useful in clinical scenarios.

Correspondence: Andrea Mariano, Department of Medicine and Health Sciences "Vincenzo Tiberio", University of Molise, Via Francesco De Sanctis 1, 86100 Campobasso, Italy.

E-mail: a.mariano989@gmail.com

Key words: Atopobium vaginae, bacterial vaginosis, bacteraemia, invasive infection, 16S rRNA gene sequencing, MALDI TOF-MS.

Acknowledgements: the authors thank Ms. Diana Isabel Fanelli for helping in the linguistic review.

Contributions: $\mathrm{AM}$ as corresponding author contributed to literature search, data collection and interpretation, to prepare tables and writing the article; all the other authors contributed equally to the drafting.

Conflict of interest: the authors declare no potential conflict of interest.

Funding: none.

Received for publication: 20 December 2018.

Revision received: 11 April 2019.

Accepted for publication: 11 April 2019.

CCopyright A. Mariano et al., 2019

Licensee PAGEPress, Italy

Microbiologia Medica 2019; 34:8014

doi:10.4081/mm.2019.8014

This article is distributed under the terms of the Creative Commons Attribution Noncommercial License (by-nc 4.0) which permits any noncommercial use, distribution, and reproduction in any medium, provided the original author(s) and source are credited.

\section{Introduction}

Atopobium vaginae (A. vaginae) is an anaerobic Gram-positive bacterium which is part of the genus Atopobium. This genus was introduced by Collins and Wallbanks in 1992 to reclassify formerly identified Lactobacillus minutus, Lactobacillus rimae and Streptococcus parvulus bacteria, demonstrating their linkage by the 16S ribosomal RNA(16S rRNA) gene sequencing (9). A. vaginae, described in 1999 (45), and Atopobium deltae in 2014, both validated by the same abovementioned method, were subsequently added to this genus. Further studies on $A$. vaginae included: bacterium identification, possible physiologic functions, its role in bacterial vaginosis (BV) onset, relationships with Gardnerella vaginalis (G. vaginalis), gynecologic-obstetric implications, its pathogenetic activities in invasive infections and an adequate prophylactic and antibiotic treatment.

The purpose of this article is to give an overview on $A$. vaginae by critically evaluating recent emerged studies in different fields, also emphasizing its clinical relevance, common traits and generally recognized characteristics, due to the availability of multiple strains.

\section{Background and clinical relevance}

A. vaginae was firstly described by Rodriguez Jovita as a Gram-positive elliptical or rod-shaped coccus bacterium, which occurs singly, in pairs or in short chains, non-mobile, asporigenous and non-capsulated, which measures approximately $0.6-0,9$ $\mu \mathrm{m}$, forming small clear colonies similar to tiny pinheads, in cultures on Columbia blood agar at $37^{\circ} \mathrm{C}$. Although being described as a facultative anaerobic bacterium (45), it was subsequently classified as a strict anaerobe $(15,19)$. The production of lactic acid (common feature of the genus Atopobium) $(5,14,23,45)$, led to assimilate $A$. vaginae function to the lactobacilli one as a component of the physiological vaginal ecosystem, which prevents the growth of undesirable microorganisms. A further biochemical characterization (analytical profile index, API), allowed the discrimination of two enzymes exclusively expressed by $A$. vaginae: histidine arylamidase and serine arylamidase (with a profile partially common to $A$. deltae, as subsequently tested, and far from other members of the genus Atopobium) $(10,45)$ (Table 1).

$A$. vaginae isolation from a healthy woman vaginal flora, in Göteborg (Sweden), suggested that it is a normal saprophyte of healthy vaginal flora $(5,45)$, with the possibility of becoming predominant in favourable conditions, such as a decrease in normal lactobacillary flora (45). This hypothesis was supported by the metabolic features of the genus Atopobium, which prefers habitats 
rich in proteins that are used as an energy source $(14,27,29)$. This scenario usually occurs in postmenopausal women, who present a reduction of vaginal epithelial cells glycogen production $(1,4,6,7)$, with a possible shift of vaginal microbiota from lactobacilli to other species. Indeed, subjects on hormone therapy have a lower incidence of $A$. vaginae (5); in fact, it has also been demonstrated that the use of vaginal estriol can lead to a recovery of the normal lactobacilli flora, with a reduced risk of infections $(5,44)$.

However, this hypothesis is not supported by the coexistence of this bacterium with $G$. vaginalis in BV (55).

Indeed, evidence suggests a direct relationship between the reduction of lactobacillary bacteria and the increase of $A$. vaginae and $G$. vaginalis in BV (2). These two species appeared specific for $\mathrm{BV}$, with $A$. vaginae being more recurrent than $G$. vaginalis. $(2,18,48)$. Furthermore, it should be noted that these two bacteria may be present with a low bacterial load in healthy women vagina without complications (20). In fact, vaginal microbiota is not a static structure (43). The cervicovaginal microflora of women is variable, according to their ethnicity, age and pregnancy status $(17,46,57)$. BV is associated with high counts of $G$. vaginalis and/or the presence of a polymicrobial biofilm containing $G$. vaginalis $(25,26,40,49,50,51,54)$. The strong adherence and the biofilm-forming capacities to vaginal epithelium suggests that $G$. vaginalis might be an initiator of the vaginal colonization, subsequently favouring adhesion of other species $(21,32,50)$, one of them being $A$. vaginae $(5,15)$. Furthermore, several molecular studies have indicated a probable role of $A$. vaginae in $\mathrm{BV}$ $(5,34,56)$ and in the establishment of a biofilm together with $G$. vaginalis $(50,51)$. Considering its presence in $80-90 \%$ of cases of relapse (2) and the in-vitro metronidazole resistance of some strains (12), A. vaginae could be relevant in BV recurrence after standard treatment with metronidazole. Although the Nugent score is the laboratory BV detection gold standard (38), its sensitivity could be compromised by interobserver variability in the vaginal smears grading $(34,55)$.

Several studies have proposed a molecular diagnosis of BV, targeting a combination of BV-related bacteria in a polymerase chain reaction (PCR), after an evaluation of the threshold concentrations of these bacteria $(30,34)$. Others suggested the fluorescence in situ hybridization (FISH), to study the biofilm structure and composition. The labelling of the cells with a fluorescent probe tailored for A vaginae (21) together with a probe for $G$. vaginalis (31) and a universal bacterial probe (41) allows to investigate the composition of vaginal biofilm in BV (22). Although further studies are needed to explain the biofilm role and the bacterial implication in $\mathrm{BV}$, there are strong indications towards the relevance of $A$. vaginae and its symbiosis with $G$. vaginalis in the biofilm pathogenic activities leading to BV onset (22).

In addition to the emphasized role in $\operatorname{BV}(2,15,22,34,39), A$. vaginae has been associated with a higher risk of preterm births $(3,35,37)$.

However, invasive infections caused by $A$. vaginae, including bacteraemia until today have been reported in only seven patients $(8,11,19,24,28,33,58)$. Although rare, these cases demonstrated the pathogenetic potential of this bacterium, especially after invasive medical-diagnostic procedures (Table 2).

\section{Diagnosis and treatment}

An accurate and rapid identification of $A$. vaginae is necessary to support the diagnosis and guide clinic interventions and treatments with the best outcomes for patients. Samples and methods used for A. vaginae detection are various, depending on the nature of the infection and its presentation. In studies carried out on BV and vaginal microflora, samples usually consist in vaginal swabs or vaginal lavage fluid $(15,45)$, while in bacteraemia and invasive infections there are different specimens, for example blood, swabs or organic material from the infection site $(8,11,19,24,28,33,58)$.

Different laboratory methods need to be considered. The Gram stain with the Nugent scoring is a BV diagnostic method, which is simple, inexpensive, and well suited to resource-limited settings, but it might present problems related to subjective interpretations. Additionally, the composition profile of the vaginal microbiota resulting from vaginal swab could be inaccurate $(6,36,38)$.

The classical culture method on plate resulted difficult to apply, although fundamental to prove the bacterium presence, considering $A$. vaginae a strict anaerobic microorganism $(15,19)$. This problem has been partially solved by the introduction of automatic systems, with a reduction in manipulation and sample collection (blood and infected liquid material) directly in anaerobic bottles.

Table 1. Differential biochemical features among members of the genus Atopobium.

\begin{tabular}{|c|c|c|c|c|c|c|}
\hline Biochemical features & A. deltae & A. fossor & A. minutum & A. paroulum & A. rimae & A. vaginae \\
\hline Acidification of D-mannose & $\mathrm{P}$ & $\mathrm{P}$ & $\mathrm{P}$ & $P$ & $\mathrm{P}$ & $\mathrm{N}$ \\
\hline Alanine arylamidase & $\mathrm{P}$ & ND & $\mathrm{N}$ & $P$ & $\mathrm{~N}$ & $\mathrm{~N}$ \\
\hline Arginine dihydrolase & $P$ & ND & $P$ & $\mathrm{~N}$ & $\mathrm{~N}$ & $\mathrm{P}$ \\
\hline Arginine arylamidase & $\mathrm{P}$ & ND & $\mathrm{P}$ & $P$ & $\mathrm{~N}$ & $\mathrm{P}$ \\
\hline Histidinearylamidase & $P$ & ND & $\mathrm{N}$ & $\mathrm{N}$ & $\mathrm{N}$ & $P$ \\
\hline b-Galactosidase & $\mathrm{N}$ & ND & $\mathrm{N}$ & $P$ & $\mathrm{~N}$ & $\mathrm{~N}$ \\
\hline Leucine arylamidase & $P$ & ND & $\mathrm{N}$ & $P$ & $\mathrm{~N}$ & $\mathrm{P}$ \\
\hline Proline arylamidase & $\mathrm{P}$ & ND & $\mathrm{P}$ & $\mathrm{N}$ & $\mathrm{N}$ & $\mathrm{P}$ \\
\hline Pyroglutamic acid arylamidase & $\mathrm{N}$ & ND & V & $P$ & $\mathrm{P}$ & $\mathrm{N}$ \\
\hline Glycinearylamidase & $\mathrm{P}$ & ND & $\mathrm{N}$ & $\mathrm{P}$ & $\mathrm{N}$ & $\mathrm{P}$ \\
\hline Serine arylamidase & $P$ & ND & $\mathrm{N}$ & $\mathrm{N}$ & $\mathrm{N}$ & $\mathrm{P}$ \\
\hline Tyrosinearylamidase & $\mathrm{P}$ & ND & $\mathrm{N}$ & $\mathrm{P}$ & $\mathrm{N}$ & $\mathrm{N}$ \\
\hline Phenylalaninearylamidase & $P$ & ND & ND & ND & ND & WP or N \\
\hline Aesculinhydrolysis & $\mathrm{N}$ & ND & ND & $\mathrm{P}$ & ND & $\mathrm{N}$ \\
\hline
\end{tabular}

Data from Cools et al. 2014 (10). N, negative; P, positive; V, variable; WP, weakly positive; ND, not determined. 
However, this diagnostic technique is time-dependent and limiting in urgencies (56).

Upon the last technological and database progresses, the Matrix-Assisted Laser Desorption/Ionization Time-of-Flight Mass Spectrometry (MALDI-TOF MS) may be a good compromise in precision, processing time and samples preparation, with the only limit in equipment costs. Indeed, its use helps in the diagnosis of almost all the invasive cases of infection caused by $A$. vaginae $(11,24,33,58)$.

Lastly, the 16S rRNA gene sequencing could be considered a useful alternative method for a rapid and accurate bacterium detection (8) and applicable upon different matrices, as demonstrated by several cases reported in literature $(8,11,19,24,28,33,58)$. Indeed, PCR assays methods are considered sensitive and specific diagnostic tools, as they can provide additional information on microbial species presence and load in a semi-quantitative and rapid manner $(13,15,18,30)$.

Regarding $A$. vaginae antimicrobial susceptibility, limited data are available. Initially, it had been proved to be resistant to metronidazole (18), with the recommendation to treat the bacterium-supported BV with clindamycin. Recently, despite these results, a metronidazole sensible strain has been isolated (47). In this regard, the study that best characterizes $A$. vaginae antimicrobial susceptibility was carried out by De Backer et al. (12), who studied nine reference bacterial strains. Data reported in literature indicate that penicillin and clindamycin are effective agents (sensitivity generally conserved), while the combination amoxicillin-clavulanic acid is the recommended therapy in most cases of invasive infections reported so far (11) (Table 2). Further studies have been carried out in order

Table 2. Summary of Atopobium vaginae invasive infections cases reported in literature

$\begin{array}{ll}\begin{array}{l}\text { Gender/Age/Patient's } \\ \text { notes }\end{array} & \text { Clinical presentation } \\ \begin{array}{ll}\text { Female/39 years/subfertility } \\ \text { due to endometriosis }\end{array} & \begin{array}{l}\text { Tubo-ovarian abscess after } \\ \text { transvaginal puncture } \\ \text { (left lower abdominal pain }\end{array} \\ & \text { for } 3 \text { days, } 2-3 \text { months after } \\ & \text { transvaginal oocyte recovery) }\end{array}$

Female/33 years/caesarean
section

Female/40 years/3 vaginal
deliveries, 1 spontaneous
miscarriage, 1 induced
abortion, 1 ectopic
pregnancy with tubal
removal

Female/33 years/4 pregnancies, 1 induced abortion and 2 vaginal deliveries

Uterine endometritis (lower abdominal pain for 3 days, malodorous vaginal discharge)

12 week pregnant; bloodstained vaginal discharge, fever, chills and vomiting after a chorionic villus sampling

Identification
method/Matrix

16S rRNA gene sequencing/Abscess swab

39 week pregnant; spontaneous maternal bacteremia with fetal distress after onset of labor (fever, fetal distress)

Female $/ 38$ years/ 3 pregnancies and 2 vaginal deliveries

16S rRNA gene
sequencing/Intrauterine
content

\section{S rRNA gene} sequencing/Blood

\section{3 week pregnant; vaginal MALDI-TOF MS and} bleeding, fever, fatigue, and myalgia in the presence of a subchorionic hematoma

16S rRNA gene sequencing/Blood
Treatment

Antimicrobials therapy:

intravenous cefoxitin and

metronidazole for 5 days and

surgical intervention

(hysterectomy, bilateral

salpingectomy, left-sided

ovariectomy, appendectomy, and adhesiolysis)

Antimicrobials therapy:

oral amoxicillin for 4 days

then intravenous meropenem for 2 days

Antimicrobials therapy: intravenous cefuroxime for 4 days and then oral amoxicillin for 2 weeks and aspiration curettage or the dead foetus removal

Antimicrobials therapy: intravenous and then oral amoxicillin clavulanate for 2 weeks, and emergency Lower segment caesarean section

Antimicrobials therapy: intravenous amoxicillin/clavulanic acid for 5 days, then oral amoxicillin for 3 weeks

Outcome

Discharged 10 days

after operation and recovery

Discharged after clinical remission with a good recovery

Foetal loss and discharge 5 days after maternal recovery

Favourable outcome, with a healthy neonate and discharge 4 days post-partum with a good maternal recovery

Favourable evolution under antibiotic therapy with spontaneous resolution of the hematoma. Preterm premature rupture of membranes at week 20 with termination of pregnancy

\begin{tabular}{ll}
$\begin{array}{l}\text { Female/29 years/healthy } \\
\text { primipara }\end{array}$ & $\begin{array}{l}\text { 39 week pregnant; } \\
\text { spontaneous maternal } \\
\text { bacteremia with fetal } \\
\text { distress after onset of } \\
\text { labor (fever, fetal distress) }\end{array}$ \\
\hline $\begin{array}{l}\text { Female/18 years/type 1 } \\
\text { diabetes with erratic } \\
\text { glycaemic control, poor } \\
\text { dental hygiene and a } \\
\text { previous vulval abscess }\end{array}$ & $\begin{array}{l}\text { Infective endocarditis } \\
\text { (reported a tricuspid valve } \\
\text { vegetation), bacteraemia, } \\
\text { abdominal pain and } \\
\text { haemoptysis }\end{array}$
\end{tabular}

MALDI-TOF MS and Antimicrobials therapy: $16 \mathrm{~S}$ rRNA gene sequencing/Blood for 3 days, then oral amoxicillin/clavulanic acid MALDI-TOF MS and $16 \mathrm{~S}$ rRNA gene sequencing/Blood Surgical excision of tricuspid valve vegetation with postoperative antimicrobials therapy: intravenous vancomycin for 4 weeks
Favourable outcome, with (11) a healthy neonate and discharge 3 days post-partum with a good maternal recovery

Favourable outcome with a good recovery
(24)

self-treated with

subcutaneous needles 
to investigate a therapeutic profile valid in BV treatment (52). Despite the resistance profiles, supported by biofilm and other bacterial species (52), nifuratel has been identified as a possible solution (53), considering its effectiveness on pathogenic strains and respectfulness of lactobacillary-resident microbial flora $(42,53)$.

\section{Conclusions and perspectives}

In conclusion, $A$. vaginae gained a relevance only in relatively recent times. With the last technological upgrades and scientific progresses, its detection and identification have become easier. This led to study and understand more about its pathogenic potential, which was unknown in the past. Firstly, considered as a normal saprophyte of the healthy vaginal flora, it is now recognized as one of the causal agents of BV and is occasionally associated to gynaecologic-obstetric complications, potentially also causing bacteraemia and invasive infections. On the basis of reported data, especially where patients referred a gynaecologic-obstetric story suggestive of bacterial infection, the presence of $A$. vaginae should be assessed during clinic evaluation and diagnostic process. Although further studies are necessary about $A$. vaginae, its role and implications result more interesting than those proposed in the past and, therefore, deserve a deeper clinical investigation.

\section{References}

1. Boskey ER, Telsch KM, Whaley KJ, et al. Acid production by vaginal flora in vitro is consistent with the rate and extent of vaginal acidification. Infect Immun 1999;67:5170-5.

2. Bradshaw CS, Tabrizi SN, Fairley CK, et al. The association of Atopobium vaginae and Gardnerella vaginalis with bacterial vaginosis and recurrence after oral metronidazole therapy. J Infect Dis 2006;194:828-36.

3. Bretelle F, Rozenberg P, Pascal A, et al. High Atopobium vaginae and Gardnerella vaginalis vaginal loads are associated with pretermbirth. Clin Infect Dis 2015;60:860-7.

4. Burton JP, Cadieux PA, Reid G. Improved understanding of the bacterial vaginal microbiota of women before and after probiotic instillation. Appl Environ Microbiol 2003;69:97-101.

5. Burton JP, Devillard E, Cadieux PA, et al. Detection of Atopobium vaginae in Postmenopausal Women by CultivationIndependent Methods Warrants Further Investigation. J Clin Microbiol 2004;42:1829-31.

6. Burton JP, Reid G. Evaluation of the bacterial vaginal flora of 20 postmenopausal women by direct (Nugent score) and molecular (polymerase chain reaction and denaturing gradient gel electrophoresis) techniques. J Infect Dis 2002;186:1770-80.

7. Cauci S, Driussi S, De Santo D, et al. Prevalence of bacterial vaginosis and vaginal flora changes in peri- and postmenopausal women. J Clin Microbiol 2002;40:2147-52.

8. Chan JF, Lau SK, Curreem SO, et al. First Report of Spontaneous Intrapartum Atopobium vaginae Bacteremia. J Clin Microbiol 2012;50:2525-8.

9. Collins MD, Wallbanks S. Comparative sequence analyses of the 16S rRNA genes of Lactobacillus minutus, Lactobacillus rimae and Streptococcus parvulus: proposal for the creation of a new genus Atopobium. FEMS Microbiol Lett 1992;74:235-40.

10. Cools P, Oyaert M, Vaneechoutte M, et al. Atopobium deltae sp. nov., isolated from the blood of a patient with Fournier's gangrene. Int J Syst Evol Microbiol 2014;64:3140-5.
11. Dauby N, Martiny D, Busson L, et al. Atopobium vaginae intrapartum bacteremia: A case report with a literature review. Anaerobe 2018. [Epub ahead of print]

12. De Backer E, Verhelst R, Verstraelen H, et al. Antibiotic susceptibility of Atopobium vaginae. BMC Infect Dis 2006; 6:51.

13. Dumonceaux TJ, Town JR, Hill JE, et al. Multiplex detection of bacteria in complex clinical and environmental samples using oligonucleotide-coupled fluorescent microspheres. J Vis Exp 2011:3344.

14. Eschenlauer SC, McKain N, Walker ND, et al. Ammonia production by ruminal microorganisms and enumeration, isolation, and characterization of bacteria capable of growth on peptides and amino acids from the sheep rumen. Appl Environ Microbiol 2002;68:4925-31.

15. Ferris MJ, Masztal A, Martin DH. Use of species-directed $16 \mathrm{~S}$ rRNA gene PCR primers for detection of Atopobiumvaginae in patients with bacterial vaginosis. J Clin Microbiol 2004;42: 5892-4.

16. Ferris MJ, Masztal A, Aldridge KE, et al. Association of Atopobium vaginae, a recently described metronidazole resistant anaerobe, with bacterial vaginosis. BMC Infect Dis 2004;4:5.

17. Fettweis JM, Brooks JP, Serrano MG, et al. Differences in vaginal microbiome in African American women versus women of European ancestry. Microbiology 2014;160:2272-82.

18. Fredricks DN, Fiedler TL, Thomas KK, et al. Targeted PCR for the detection of vaginal bacteria associated with bacterial vaginosis. J Clin Microbiol 2007;45:3270-6.

19. Geißdörfer W, Böhmer C, Klaus Pelz K, et al. Tuboovarian Abscess Caused by Atopobiumvaginae following Transvaginal Oocyte Recovery. J Clin Microbiol 2003;41:2788-90.

20. Genc MR, Onderdonk A. Endogenous bacterial flora in pregnant women and the influence of maternal genetic variation. BJOG 2011;118:154-63.

21. Hardy L, Jespers V, Dahchour N, et al. Unravelling the bacterial vaginosis-associated biofilm: a multiplex Gardnerella vaginalis and Atopobium vaginae fluorescence in situ hybridization assay using peptide nucleic acid probes. PLoS One 2015;10:e0136658.

22. Hardy L, Jespers V, Abdellati S, et al. A fruitful alliance: the synergy between Atopobium vaginae and Gardnerella vaginalis in bacterial vaginosis-associated biofilm. Sex Transm Infect 2016;92:487-91.

23. Harmsen HJ, Wildeboer-Veloo AC, Grijpstra J, et al. Development of $16 \mathrm{~S}$ rRNA-based probes for the Coriobacterium group and the Atopobium cluster and their application for enumeration of Coriobacteriaceae in human feces from volunteers of different age groups. Appl Environ Microbiol 2000;66:4523-7.

24. Jacqmin H, deMunter P, Verhaegen J, et al. Atopobium vaginae bacteremia associated with a subchorionic hematoma. Clin Microbiol Newsl 2017;40:83-5.

25. Jespers V, Crucitti T, van de Wijgert JH, et al. A DNA tool for early detection of vaginal dysbiosis in African women. Res Microbiol 2016;167:133-41.

26. Jespers V, van de Wijgert J, Cools P, et al. The significance of Lactobacillus crispatus and L. vaginalis for vaginal health and the negative effect of recent sex: a cross-sectional descriptive study across groups of African women. BMC Infect Dis 2015;15:1-14.

27. Kazor CE, Mitchell PM, Lee AM, et al. Diversity of bacterial populations on the tongue dorsa of patients with halitosis and healthy patients. J Clin Microbiol 2003;41:558-63.

28. Knoester M, Lashley LE, Wessels E, et al. First report of Atopobium vaginae bacteremia with fetal loss after chorionic villus sampling. J Clin Microbiol 2011;49:1684-6. 
29. Kumar PS, Griffen AL, Barton JA, et al. New bacterial species associated with chronic periodontitis. J Dent Res 2003;82:338-44.

30. Kusters JG, Reuland EA, Bouter S, et al. A multiplex real-time PCR assay for routine diagnosis of bacterial vaginosis. Eur J Clin Microbiol Infect Dis 2015;34:1779-85.

31. Machado A, Almeida C, Salgueiro D, et al. Fluorescence in situ hybridization method using peptide nucleic acid probes for rapid detection of Lactobacillus and Gardnerella spp. BMC Microbiol 2013;13:82.

32. Machado A, Cerca N. The influence of biofilm formation by Gardnerella vaginalis and other anaerobes on bacterial vaginosis. J Infect Dis 2015;212:1856-61.

33. Mansell J, Gourtsoyannis Y, Draz N, et al. Infective endocarditis due to Atopobium vaginae: a rare association between genital infection and endocarditis of the tricuspid valve. BMJ Case Rep 2018:bcr-2018-225871.

34. Menard JP, Fenollar F, Henry M, et al. Molecular quantification of Gardnerella vaginalis and Atopobium vaginae loads to predict bacterial vaginosis. Clin Infect Dis 2008;47:33-43.

35. Menard JP, Mazouni C, Salem-Cherif I, et al. High vaginal concentrations of Atopobium vaginae and Gardnerella vaginalis in women undergoing preterm labor. Obstet Gynecol 2010;115:134-40.

36. Money D. The laboratory diagnosis of bacterial vaginosis. Can J Infect Dis Med Microbiol 2005;16:77-9.

37. Muzny CA, Blanchard E, Taylor CM, et al. Identification of Key Bacteria Involved in the Induction of Incident Bacterial Vaginosis: A Prospective Study. J Infect Dis 2018;218:966-78.

38. Nugent RP, Krohn MA, Hillier SL. Reliability of diagnosing bacterial vaginosis is improved by a standardized method of gram stain interpretation. J Clin Microbiol 1991;29:297-301.

39. Onderdonk AB, Delaney ML,Fichorova RN. The Human Microbiome during Bacterial Vaginosis. Clin Microbiol Rev 2016;29:223-38.

40. Patterson JL, Stull-Lane A, Girerd PH, et al. Analysis of adherence, biofilm formation and cytotoxicity suggests a greater virulence potential of Gardnerella vaginalis relative to other bacterial-vaginosis-associated anaerobes. Microbiology 2010; 156:392-9.

41. Perry-O'Keefe H, Stender H, Broomer A, et al. Filter-based PNA in situ hybridization for rapid detection, identification and enumeration of specific micro-organisms. J Appl Microbiol 2001;90:180-9.

42. Polatti F. Bacterial vaginosis, Atopobium vaginae and nifuratel. Curr Clin Pharmacol 2012;7:36-40.

43. Ravel J, Gajer P, Abdo Z, et al. Vaginal microbiome of reproductive-age women. Proc Natl Acad Sci USA 2011;108:4680-7.

44. Raz R, Stamm WE. A controlled trial of intravaginal estriol in postmenopausal women with recurrent urinary tract infections. N Engl J Med 1993;329:753-6.
45. Rodriguez Jovita M, Collins MD, Sjödén B, et al. Characterization of a novel Atopobium isolate from the human vagina: description of Atopobium vaginae sp. nov. Int J Syst Bacteriol 1999;49:1573-6.

46. Romero R, Hassan SS, Gajer P, et al. The composition and stability of the vaginal microbiota of normal pregnant women is different from that of non-pregnant women. Microbiome 2014;2:4

47. Schuyler JA, Mordechai E, Adelson ME, et al. Draft Genome Sequence of a Metronidazole-Susceptible Atopobium vaginae Isolate. Genome Announc 2015; e00991-15.

48. Shipitsyna E, Roos A, Datcu R, et al. Composition of the vaginal microbiota in women of reproductive age-sensitive and specific molecular diagnosis of bacterial vaginosis is possible? PloS One 2013;8:e60670.

49. Srinivasan S, Hoffman NG, Morgan MT, et al. Bacterial communities in women with bacterial vaginosis: high resolution phylogenetic analyses reveal relationships of microbiota to clinical criteria. PLoS One 2012;7:e37818.

50. Swidsinski A, Loening-Baucke V, Mendling W, et al. Infection through structured polymicrobial Gardnerella biofilms (StPMGB). Histol Histopathol 2014;29:567-87.

51. Swidsinski A, Mendling W, Loening-Baucke V, et al. Adherent biofilms in bacterial vaginosis. Obstet Gynecol 2005; 106:1013-23.

52. Swidsinski A, Mendling W, Loening-Baucke V, et al. An adherent Gardnerella vaginalis biofilm persists on the vaginal epithelium after standard therapy with oral metronidazole. Am J Obstet Gynecol 2008;198:97.e1-6.

53. Togni G, Battini V, Bulgheroni A, et al. In vitro activity of nifuratel on vaginal bacteria: could it be a good candidate for the treatment of bacterial vaginosis? Antimicrob Agents Chemother 2011;55:2490-2

54. van de Wijgert JH, Borgdorff $H$, Verhelst $\mathrm{R}$, et al. The vaginal microbiota: what have we learned after a decade of molecular characterization? PLoS One 2014;9:e105998.

55. Verhelst R, Verstraelen H, Claeys G, et al. Cloning of $16 \mathrm{~S}$ rRNA genes amplified from normal and disturbed vaginal microflora suggests a strong association between Atopobium vaginae, Gardnerella vaginalis and bacterial vaginosis. BMC Microbiol 2004;4:16.

56. Verstraelen H, Verhelst R, Claeys G, et al. Culture-independent analysis of vaginal microflora: the unrecognized association of Atopobium vaginae with bacterial vaginosis. Am J Obstet Gynecol 2004;191:1130-2.

57. Walther-António MRS, Jeraldo P, Berg Miller ME, et al. Pregnancy's stronghold on the vaginal microbiome. PloS One 2014;9:e98514.

58. Yamagishi Y, Mikamo H, Tanaka K et al. A case of uterine endometritis caused by Atopobium vaginae. J Infect Chemother 2011;17:119-21. 